\title{
MEMORIA, CONEXIONES Y DESCONEXIONES: POR UNA ANTROPOLOGÍA DE LA VULNERABILIDAD ${ }^{1}$ MEMÓRIA, CONEXÕESE DESCONEXÕES: POR UMA ANTROPOLOGIA DA VULNERABILIDADE
}

\author{
MEMORY, CONNECTIONS AND DISCONNECTIONS: \\ TOWARDS AN ANTHROPOLOGY OF VULNERABILITY
}

\section{Nicolás Guigou²}

\begin{abstract}
Sólo escribimos en la extremidad de nuestro saber, en ese punto extremo que separa nuestro saber y nuestra ignorancia, y que hace pasar el uno dentro de la otra. Sólo así nos decidimos a escribir. Colmar la ignorancia es postergar la escritura hasta mañana, o más bien volverla imposible. Tal vez la escritura mantenga con el silencio una relación mucho más amenazante que la que se dice mantiene con la muerte.
\end{abstract}

Deleuze, Gilles. Différence et répétition.

\section{RESUMEN}

Indagamos en un espacio etnográfico específico (La Colonia rusa de San Javier, Uruguay), los estilos de construir memorias a través de narrativas atravesadas por conexiones y desconexiones temporales. Construyendo un montaje antropológico, tratamos de ahondar en una antropología de la vulnerabilidad, en este caso interpelada y conformada por los tiempos del Terror vividos por los habitantes de la citada Colonia.

Palabras claves: Memoria. Narrativa. Vulnerabilidad. San Javier. Uruguay.

\footnotetext{
${ }^{1}$ Este trabajo constituye parte de la Tesis de Doctorado en Antropología Social del que suscribe. Ver: Guigou (2008b).

2 Dr. L. Nicolás Guigou. Profesor Adj. del Dpto. de Antropología Social (FHCE, UDELAR) y Prof. Agr. de la Cátedra de Antropología Cultural (LICCOM, UDELAR), Integra el Sistema Nacional de Investigadores (SNI), ANII, Uruguay.
} 


\section{RESUMO}

Indagamos num espaço etnográfico específico (a Colônia russa de San Javier, no Uruguai), os estilos de construir memórias por meio de narrativas atravessadas por conexões e desconexões temporais. Construindo uma montagem antropológica, tentamos aprofundar numa antropologia da vulnerabilidade, neste caso interpelada e formada pelos tempos do Terror vividos pelos habitantes da citada Colônia.

Palavras-chave: Memória. Narrativa. Vulnerabilidade. San Javier, Uruguai.

\section{ABSTRACT}

We investigated within a specific ethnographic space (the Russian community in San Javier, Uruguay) the styles of building memories through narratives crossed by temporal connections and disconnections. By building an anthropological staging, we tried to deepen even more within an anthropology of vulnerability, in this case questioned and made up of the Terror times lived by the inhabitants of such Community.

Keywords: Memory. Narrative. Vulnerability. San Javier. Uruguay.

\section{ENTRADAS}

Una antropología de la vulnerabilidad supone que todo encuentro etnográfico amplifica a la misma, en la medida que las posibilidades de la antropología se encuentran en abordar, ser parte, atravesar la vulnerabilidad, en tanto la vulnerabilidad es el Otro. El espacio de narración de la vulnerabilidad, el intento de gestar este espacio, parece, al inicio, baladí.

Es que no podría haber antropología sin esa vulnerabilidad. Porque la vulnerabilidad es precisamente el Otro, la posibilidad de emergencia del Otro.

Ese Otro se desliza hacia el rostro, hacia su propia rostrocidad. Habría así en el rostro, en la rostrocidad una temática axial que da espacio a la vulnerabilidad. El Otro se presenta ante mí mediante su rostro. ¿Pero qué es el rostro del Otro? Por una parte tenemos la rostrocidad clásica, la superficie en la cual el rostro desaparece, ese rostro tipo medio europeo, al decir de Gilles Deleuze (DELEUZE; PARNET, 1980).

Allí el rostro es pura codificación: es la luz blanca sobre la pared con agujeros negros.

La imagen terrible de la inanidad del rostro, del poder enrostrado. El rostro se ajusta aquí a una función: es el triunfo de la razón instrumental. Pero también el rostro, la rostrocidad, llama a la vulnerabilidad. El rostro del Otro es el que se me presenta como posibilidad de abertura. Una abertura que tiene que ver no únicamente con el rostro único, singular. El rostro es también discurso desde donde el Otro se expresa, corporeidad, movimientos (LEVINAS, 1995). Desde esta vulnerabilidad y esos rostros, estas escrituras intentan ser parte de un conjunto de entramados etnográficos que comienzan antes y evi- 
dentemente, terminan después del que escribe (e inscribe) este texto. Dar punto final a una investigación parece resultar una de las tantas ficciones etnográficas.

Porque, ¿cómo librarse de los encuentros y desencuentros, los olvidos, las temporalidades, las memorias y los recorridos que se van gestando en y durante el propio trabajo de campo?

No hay posibilidad para el punto final. Y el duelo, que acompaña el final de una investigación, también es percudido por un tiempo que está fuera del tiempo, pero que a la vez lo hace posible. Hay una temporalidad que no es ni remotamente social e histórica, pero que tampoco puede dejarse abandonada a sí misma. En otro lugar ${ }^{3}$ hacíamos referencia a que los sujetos no agotan sus posibilidades simbólicas bajo tal o cual moldura sociocultural.

En esos mundos virtuales, en esas modalidades que zigzaguean esta suerte de mundo real, es que puede apenas percibirse -como en el relampagueo benjaminiano- las temporalidades del afuera que atraviesan y horadan tanto el manido tiempo social que heredamos de Durkheim (2007), así como las diferentes temporalidades presentes en un espacio etnográfico.

Estamos pues en la máquina del tiempo, con Mnemosina a la cabeza. Habrá que recordar -y para ello, está Mnemosina, la propia diosa de La Memoria-, que la misma es la madre de las musas. Ya con estos antecedentes familiares, la memoria se aleja de la figura de un mero depósito de recuerdos, para tomar el lugar que le corresponde: una fuente inagotable de creaciones y recreaciones.

Lejos de las Musas, resulta comprensible que las culturas que han pasado por períodos de Terror -como es el caso uruguayo- no dejen de cosificar a la memoria, transformándola así en un objeto que eventualmente puede perderse, ganarse, e inclusive rescatarse. Emerge así la necesidad de rescatar ese tesoro ocultado por prácticas represoras, que anidan (o anidaban) en un espacialidad intermitente, escondida entre las cámaras de tortura y los campos de concentración.

El borrado de la huella por aquellos que tramaron las dictaduras militares o los holocaustos, se transforma bajo esta operativa en la huella misma. Así, la memoria queda subsumida a los períodos de Terror en los que tuvo alguno de sus pasajes -y todas las memorias serán únicamente esa memoria- o bien, se considera al Terror como un estado de excepción y por lo tanto, se lo absolutiza, corriendo el riesgo de extraerlo de (inclusive) la propia reificación del tiempo histórico. El Terror como estado de excepción, esa ingenuidad ya refutada por Walter Benjamín (1973), solamente puede sostenerse bajo el dispositivo de una ahistoricidad específica.

Por este recorrido, el Terror es tan absoluto -los Terrores que han habido, los que vienen y los que vendrán (¿pero cómo no aterrorizar los rituales sociales que derivan del

3 Ver sobre este punto: Guigou (2008a). 
propio Terror?)-, que el mismo solamente puede experimentarse como un estado de excepción, una irrealidad. De allí su vinculación con el mundo onírico y la irrealidad que rodea -y constituye- los momentos, períodos y situaciones de Terror que lo hacen vincularse con lo indecible y lo inenarrable.

Hay con todo, un problema tal vez más importante con los ejercicios de rescate de la memoria. La memoria como un bien a rescatar, no podría nunca dialogar con el conocimiento socio-cultural implícito y el Terror descansa en ese pliegue: es difícil (y duro) admitir que ese conocimiento socio-cultural implícito sabía lo que estaba sucediendo bajo el propio Terror. Si nos adentramos en el perspectivismo del conocimiento socio-cultural implícito, nos desacoplamos de la idea de un sujeto de conciencia, que en esa breve pantalla, "ganaría" o "perdería" la memoria. Pero dado que es el propio Terror (ahora metafísico) el que postula un sujeto de conciencia, una de las maneras de salvar ese extraño producto socio-cultural (curiosamente, también histórico) llamado sujeto de conciencia, descansa justamente en las estrategias del discurso histórico. Desde allí, desplegando ese discurso, no tendremos más que rescates, pérdidas y restituciones de la memoria.

Flaco favor, sin duda, para las generaciones que fueron y las que están por venir. Pero tratemos de equilibrar la balanza: ya admitida que las cronologías y nuestra manera de adentrarnos en la historia, es, precisamente nuestra, ya antropológicamente relativizadoe historizado- el propio conocimiento historiográfico, un conjunto de saberes que entrecruzan disciplinas varias, remiten a modalidades de dialogar con nuestras tradiciones, nuestras temporalidades y nuestros mitos desde otros lugares.

Estas singularidades culturales, que organizan las temporalidades e historicidades de diferente manera, producen lugares.

Lugares que no llaman necesariamente ni a los espectros de la "verdad histórica" -un absolutismo disciplinario siempre en ciernes- $\mathrm{ni}$ al caleidoscopio de las múltiples visiones y perspectivas que se afincan en un relativismo radical. Hay hilos, hilos de la memoria, que hacen saltar ese recorrido lineal del tiempo intervenido históricamente.

Este tiempo plagado de vacíos y continuidades -imagen opuesta al deseado tiempoahora de Walter Benjamín (1973)- no llama precisamente a anaqueles y libros empolvados. Todo esto me los hizo recordar -pensando en el tiempo y la memoria -Ana Chimailov, uno de los seres más poéticos (y por eso más sábios) que he conocido en mi vida.

Ana era una decidida "guardiana de la memoria", una narradora por excelencia. A diferencia del narcisista intelectual obsesionado por sí mismo - el gesto del intelectual que escenifica públicamente que solamente le interesó su vida, obligando a algún público cautivo a hacerse cargo de lo relevante que fue su transcurso vital (una aceitada lección de antiantropología)-, Ana iba (ya falleció) narrando una historia poblada de otras y otras voces, y ella era parte de esas otras voces también. Toda una manera pues de hacer antropología en aquella mujer que vivía en una casa de barro típicamente rusa, que pasaba los noventa años y que poseía el visionar de algunas cegueras singulares. 


\section{Ana Chimailov: una cartógrafa del tiempo y la memoria.}

El cronista que narra los acontecimientos sin distinguir entre los grandes y los pequeños, da cuenta de una verdad: que nada de lo que una vez haya acontecido ha de darse por perdido para la historia. Por cierto, que sólo para la humanidad redimida se ha hecho su pasado citable en cada uno de sus momentos. Cada uno de los instantes vividos se convierte en una citación à l' ordre du jour, pero precisamente del día final.

Walter Benjamin. Tesis de filosofía de la historia.

El montaje, como imbricación identitaria y visión etnográfica, trataría de recuperar un tiempo-ahora, contrario en todos sus términos a un tiempo vacío y homogéneo. Intentar dar el salto entre el presente y el pasado por medio de imágenes que se mezclan y se interpenetran, a través de tramas narrativas, implica admitir las discontinuidades y continuidades en el propio arte del narrar.

Como escribe (y narra) el propio Walter Benjamin (2005, p. 464):

No es que el pasado arroje luz sobre lo presente, o lo presente sobre lo pasado, sino que imagen es aquello en donde lo que ha sido se une como un relámpago al ahora en una constelación. En otras palabras: imagen es la dialéctica en reposo. Pues mientras que la relación del presente con el pasado es puramente temporal, continua, la de lo que ha sido con el ahora es dialéctica; no es un discurrir, sino una imagen, en discontinuidad.

El montaje permite trabajar varias temporalidades, entrar y salir de grupos y sujetos, sin postular modelos universales y sí espacios de conexiones y desconexiones. Así, retomando el projeto benjaminiano de montaje, Taussig $(1993$, p.413) reflexiona acerca de esta estrategia etnográfica y comunicacional:

Montaje: focalizar hacia el frente y hacia atrás, partiendo del individuo para el grupo; no se trata simplemente de auto-absorción, interrumpida y descartada por medio de la participación en el grupo o con uno o dos miembros de él, a través de esa focalización hacia el frente y hacia atrás, del individuo para el grupo y viceversa, se establece una especie de espacio lúdico y de un espacio para testear, con el fin de que se pueda comparar las alucinaciones con los campos sociales de las cuales ellas emanan. Entonces, el propio espacio de representación es escudriñado.

Siguiendo esta modalidad de montaje, en este trabajo intento anudar diversas temáticas que se han ido elaborando a partir del trabajo de campo que llevé a cabo en la Colonia San Javier (Dpto. de Río Negro, Uruguay). Los núcleos temáticos tienen que ver con 
algunas preocupaciones en torno a la imposición de una suerte de identidad nacional totalizadora, y, en ese marco tensional, las labores performáticas de los sujetos que poseen tradiciones culturales singulares (y singularizadas).

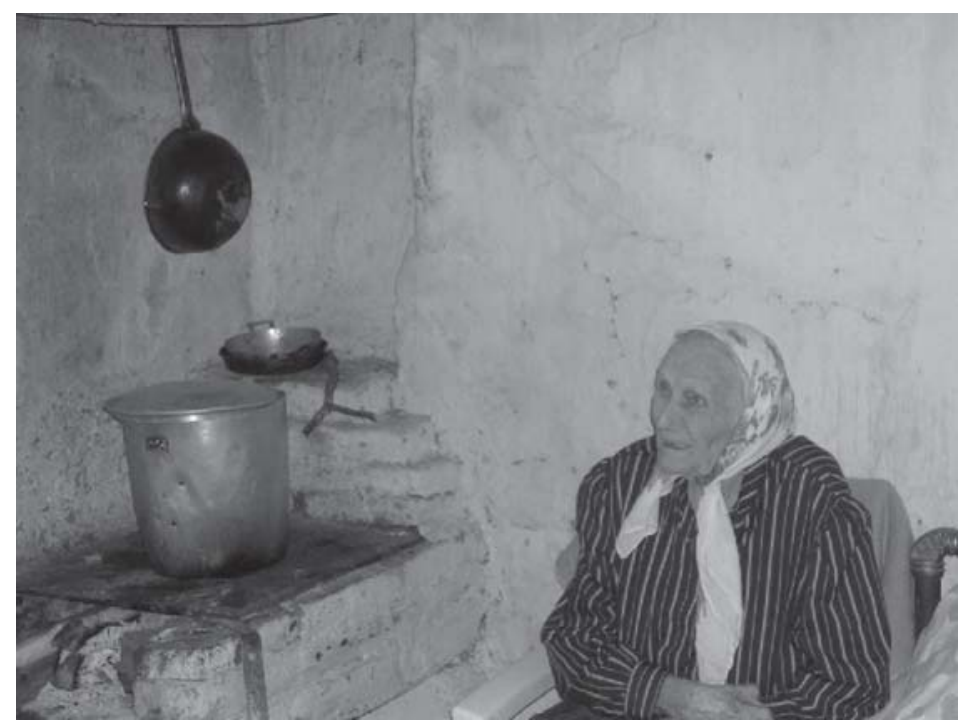

Ana Chimailov en su casa de barro.

Foto n 1: L. Nicolás Guigou, San Javier, Uruguay, jul./2005.

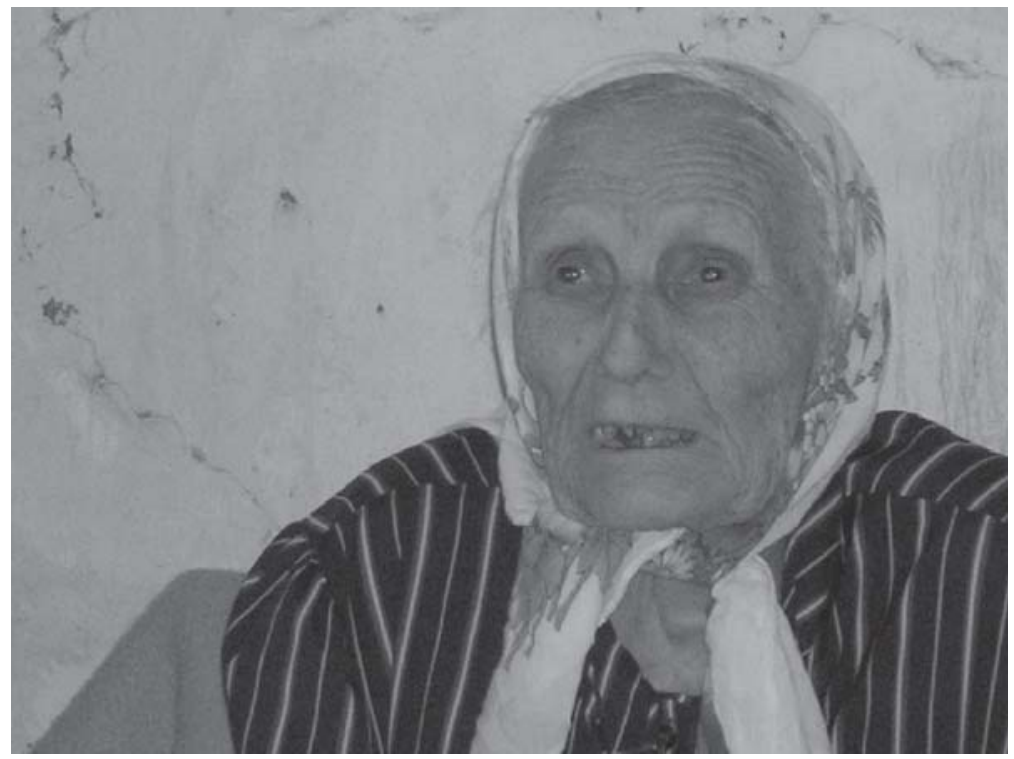

Foto n. 2: L. Nicolás Guigou, San Javier, Uruguay, 2005. 
y que señalan otros tiempos y otros espacios, mas allá (o más acá) de las narrativas homogéneas y sacralizadas del Estado-Nación.

Estamos pues, en la máquina del tiempo, la religión fundante (para el caso de San Javier), y la pluralidad de memorias, que se constituyen en múltiples trayectorias, conflictivas, azarosas, y profundamente signadas por cristalizaciones de sentido, que muestran -una y otra vez- a las memorias en diversos niveles de conflictividad.

Pero tal vez la temática del conflicto sea una de las modulaciones de la memoria: se trata pues de ir directamente a esa conflictividad.

Por eso hacemos referencia a un anudar que se ha ido elaborando.

No está pues en un locus de reflexividad autónoma del antropólogo, ni tampoco de dar la voz a aquellos que no tiene voz porque sí la tienen. Con todo, no hay que desconocer una labor de cierta restitución. ¿Pero restitución de qué?

Ha habido en las exposiciones de la antropología objetivista, el intento de transformar las diferentes narrativas en cosas, en meros objetos a disposición del investigador.

De esta forma, el narrador viene a ejemplificar las afirmaciones del antropólogo: breves notas demostrativas que quedan subsumidas a un saber mayor y abarcativo. Esta modalidad extractiva de algunas antropologías, podría considerarse tal vez como una de las tantas formas de despojo a los que se encuentran sometidos los sujetos "antropologizados", en particular cuando se trata de voces que a pocos interesa escuchar.

Ahora bien, contra ese desinterés, es que adviene la necesidad de restitución, en la que medida que en esa discontinuidad, en esa pérdida del narrar, en esas destituciones de la memoria, en esa progresiva anulación de los sujetos que narran, toda una política está en juego.

Las memorias de los que viven y de los que han vivido, atentan contra un "presente permanente" que lo que hace es fagocitar el pasado, interrumpir el arte de narrar- ese tiempo fuera del tiempo- y particularmente, anular las transversalidades intergeneracionales.

De este modo, la "cita secreta" entre las generaciones anteriores y la nuestra, esa cita anhelada por Benjamín (1973) queda apenas como una amenazante y por eso siempre postergada posibilidad.

De Ana me siento muy cerca, casi conmovido.

Sus manos son enormes, huesudas. Hay muchas manos así, en San Javier. Sus ojos que no ven, están llenos de vida. Con más de noventa años, porta su vejez de una manera extraña, tan alejada de la degradación de los viejos -curiosa destrucción de los viejos, en un país de viejos- y es feliz contando.

Vive en una pequeña casa rusa de barro, que tiene tantos años como ella.

Alguien que ha llegado con sabiduría a su vejez.

El tiempo de Ana es otro tiempo. La espacialidad de su ceguera, también.

Ana mira para adentro, y canta una canción de niños en ruso:

"Se volaron, se volaron, en la cabeza se sentaron..." 
Ella llegó muy chica al Uruguay, de su lejana Rostov, junto a una muchedumbre de seguidores de la corriente religiosa "Nueva Israel", perseguidos por el zarismo y la Iglesia Ortodoxa Rusa.

Hablamos mucho de Basilio Lubkov, el líder religioso de la comunidad, de la fundación de la Colonia en 1913, y de la posterior vuelta de Lubkov -seguido por un conjunto de acólitos- a la URSS.

El tema de la muerte de Roslik aparece de manera inevitable:

Como mi marido trabajaba en la polclínica...él (Roslik) venía siempre a preguntar quién estaba enfermo, qué le hacían, dónde lo mandaban, qué enfermedad, que se yo...Sabía todo.

Venía de noche, a veces hasta tarde estaba. Yo me acostaba y ellos estaban conversando siempre. Valodia...cómo no lo voy a conocer.

Era buenazo, un pedazo de pan (...) Lo envolvieron. Mintieron que él traía armamento de la Argentina y lo escondía ahí... En Barranca - le decían "Cueva del Indio"-, unas grutas, este, unos cerros de toscas, decían que las escondía allá. Y el nunca fue a la Argentina, nunca... Mintieron. Y bueno, lo llevaron preso. Y no quería hablar. iQué va a hablar! Dicen: "lo mataron porque no hablaba". Qué va a hablar si no sabía nada. ¿Cómo va a mentir, no? Hablar sí. Hablaba lo que preguntaba la policía allá en Fray Bentos. Y lo que no sabía iqué iba a hablar! Dicen: "lo mataron porque no habló". Qué iba a hablar ¿la mentira esa que lo envolvieron? Mintieron a troche y moche. Mentiras de la gente...de la gente de acá nomás...le tenían rabia... de locos que son.

Era buenazo, un pedazo de pan. Cuando iba al cementerio, iba siempre al Panteón de él. Iba al Panteón de la Scorina también.

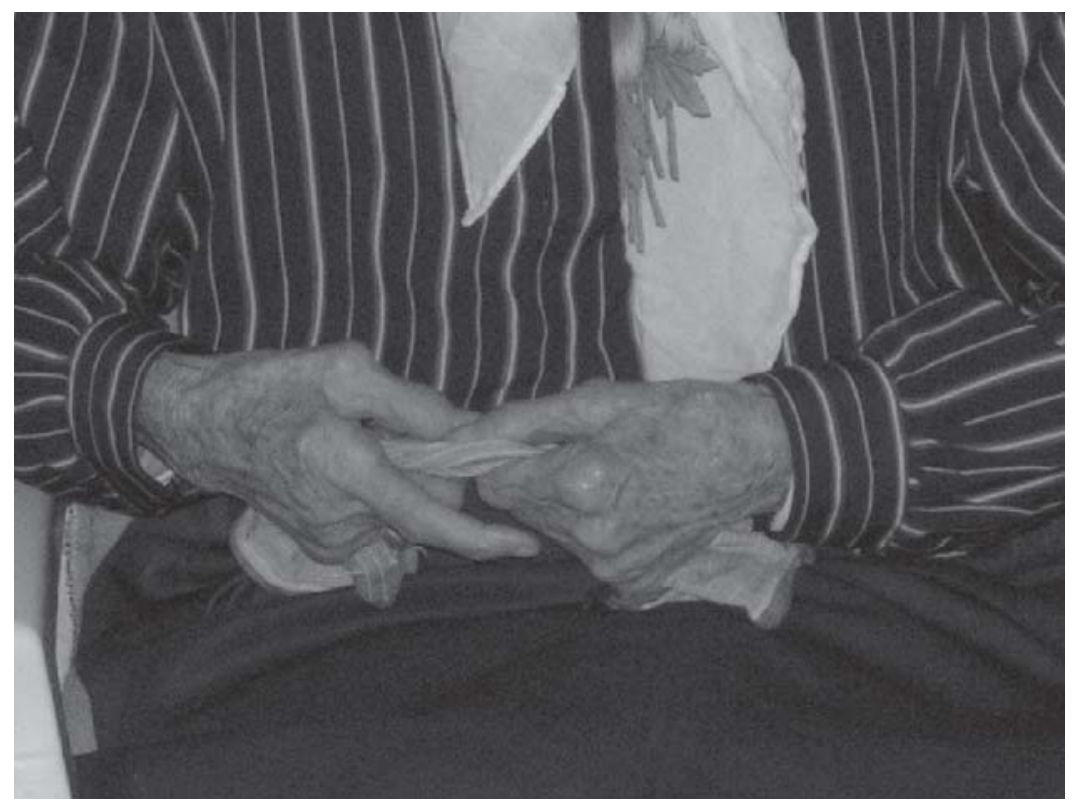

Hablando con las manos.

Foto n. 3: L. Nicolas Guigou, San Javier, Uruguay, jul/2005. 
Es una larga historia, un hilo de la memoria que Ana va tejiendo bajo diferentes ritmos. El nombre de Scorina abre otro espacio de la memoria. Hacia -en el tiempo cronológico- unas décadas atrás.

\begin{abstract}
Algunos se juntaban, tenían un Comité. Quedó la casa y mataron a una mujer los policías. Julia Scorina...Quedó el hijo...La mataron los policías. Hicieron una gran conferencia acá en San Javier. Estaba la Policía tiroteando por ahí. La mataron los policías [...] Cuando vino la policía yo no fui. Julia Scorina era una integrante del Partido Comunista. Había una conferencia muy grande. Acá cerca nomás, en San Javier. Mucha gente había. Y había unos policías que sabían hablar en ruso. Entre los rusos aprendieron...de acá, nomás...¿¿Cómo era que se llamaba? Juan Carlos Martínez. Juan Carlos Martínez. Hablaba, cantaba ruso, aprendió de los rusos. Cantaba. Ellos estaban ahí...como lo mandaban siempre, como no entienden los otros, idioma uruguayo nomás, no entienden ruso, lo mandaban a todas partes. Lo mandaban a él. Dicen "va para enterarse de algo". Hacía espionaje. Y el hermano de él era Comisario...Amado Martínez. Era una conferencia de los comunistas. Y ahí mataron a Julia Scorina. Cuando ella empezó a hablar, ella subió al palco y ahí nomás la mataron.
\end{abstract}

Los tiempos se yuxtaponen en la narrativa de Ana. Podríamos hablar del historiar: la muerte de Julia Scorina en la década de los '30, la muerte de Roslik en los '80. Pero Ana no se confunde. El tiempo vacío y homogéneo subrayado por Walter Benjamin como escritura enferma del historiador, no está presente en la trama de su memoria.

Cuando hablamos de los militares y de su accionar en San Javier,

Ana me sorprende con la pregunta: ¿éstos últimos? Ana se acuerda de varias veces de policías y militares. Ahora me cuenta de "estos últimos militares", del cotidiano en San Javier.

...Estaba brava. Agarraban y metían a cualquiera y mentían y todo. El que no le servían [...] Porque nadie les hacía caso. Nadie. Todos callados...todos le tenían miedo, la población.

A él (Roslik) lo llevaron. Lo molestaban. Nunca fue a la Argentina, nunca trajo armas, no precisaba. Lo mintieron nomás. Lo mandaron a la muerte".

"Lo mandaron a la muerte". Mandar a alguien a ese otro espacio, a la muerte. "Lo mandaron a la muerte". Con esa poética minimalista de la muerte, con esa frase, nuestro diálogo hace una pausa profunda. Ana mira sin mirar con sus ojos ciegos hacia la ventana. $\mathrm{O}$ tal vez mira ese otro tiempo -el tiempo del terror- apenas narrable. Sigue un silencio poblado de gestos delicados, como protegiendo -tal vez exorcizando- el tiempo de la muerte, del terror. 


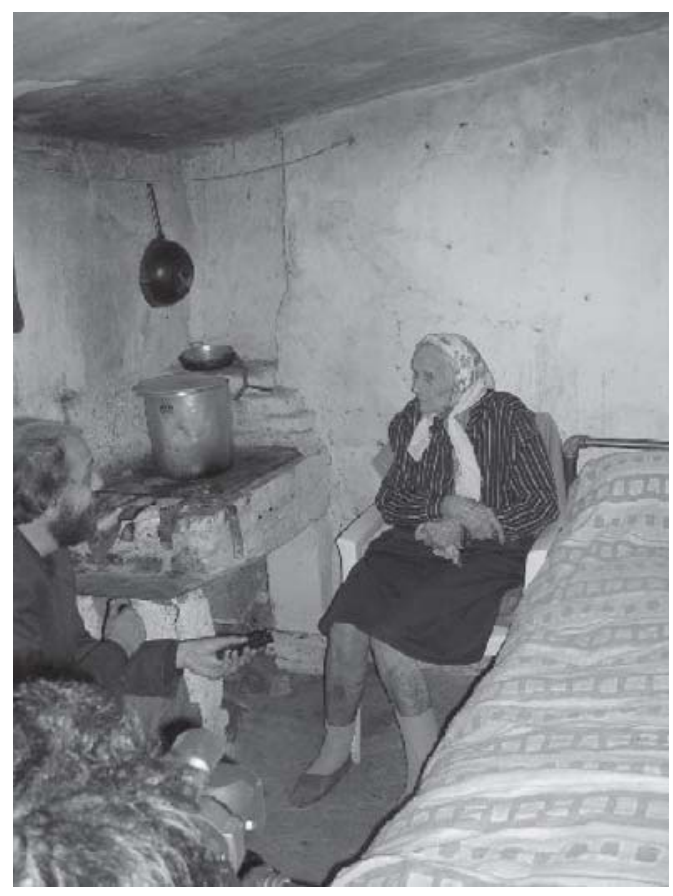

Foto n 4: Daniel Barceló, San Javier, Uruguay, 2005.

\section{REFERÊNCIAS BIBLIOGRÁFICAS}

BENJAMIN, Walter. Libro de los pasajes. Madrid: Akal, 2005. 1102 p.

BENJAMIN, Walter. Discursos interrumpidos. Madrid: Taurus, 1973.

DELEUZE, Gilles; PARNET, Claire. Diálogos. Valencia, Pre-Textos, 1980. 166 p.

DURKHEIM, E. Las formas elementales de la vida religiosa. México D.F.: Colofón, 2007.

GUIGOU, L. Nicolás. Acerca de fronteras, nominaciones y efectos teóricos. In: BASINII, José; GUIGOU, L. Nicolás. Fronteras, diálogos e intervención social en el contexto Pan-amazónico. Montevideo: Universidad de la República, Universidad de Guadalajara, Universidade Federal do Amazonas, 2008. p. 46-70a.

GUIGOU, L. Nicolás. Religião e produção do outro: mitologias, memórias e narrativas na construção identitária das correntes imigratórias russas no Uruguai. 2008b. 334 f. Tese (Doutorado em Antropología Social)Programa de Pos-graduação em Antropologia Social, Porto Alegre. Disponível em: <http://www.lume.ufrgs.br/ handle/10183/14948>. Acesso em: 05 fev. 2010.

LEVINAS, Emmanuel. Totalidad e infinito: ensayo sobre la exterioridad. Salamanca: Sígueme, 1995. 315 p.

TAUSSIG, Michael. Xamanismo, colonialismo e o homem selvagem. Sao Paulo: Paz e Terra, 1993. 481 p. 